This is a provisional PDF only. Copyedited and fully formatted version will be made available soon.

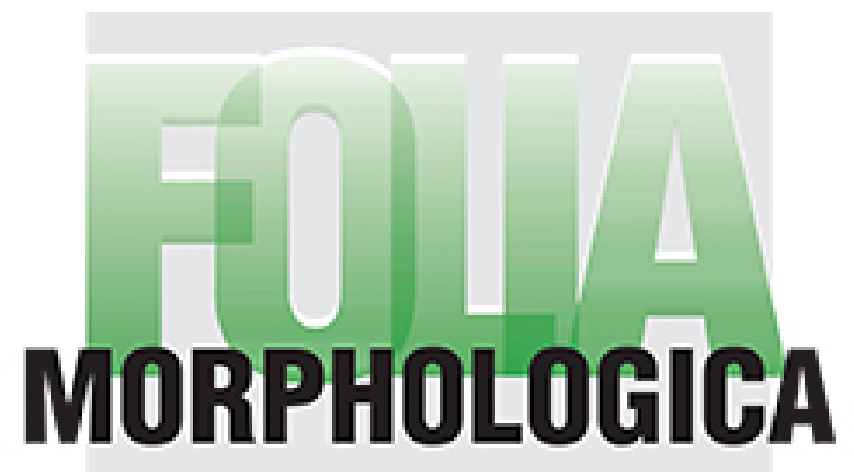

ISSN: 0015-5659

e-ISSN: $1644-3284$

\title{
Anatomical variations of the biceps brachii insertion: a proposal for a new classification
}

Authors: B. Szewczyk, F. Paulsen, R. F. LaPrade, A. Borowski, N. Zielinska, Ł. Olewnik

DOI: 10.5603/FM.a2022.0022

Article type: Original article

Submitted: $2021-10-02$

Accepted: $2022-01-17$

Published online: $2022-02-28$

This article has been peer reviewed and published immediately upon acceptance.

It is an open access article, which means that it can be downloaded, printed, and distributed freely, provided the work is properly cited.

Articles in "Folia Morphologica" are listed in PubMed. 
Anatomical variations of the biceps brachii insertion: a proposal for a new classification B. Szewczyk et al., Biceps brachii insertion

B. Szewczyk ${ }^{1}$, F. Paulsen ${ }^{2,3}$, R.F. LaPrade ${ }^{4}$, A. Borowski ${ }^{5}$, N. Zielinska ${ }^{1}$, Ł. Olewnik ${ }^{1}$

${ }^{1}$ Department of Anatomical Dissection and Donation, Medical University of Lodz, Poland ${ }^{2}$ Institute of Functional and Clinical Anatomy, Erlangen, Germany

${ }^{3}$ Sechenov University, Department of Topographic Anatomy and Operative Surgery, Moscow, Russia

${ }^{4}$ Twin Cities Orthopedics, Edina, Minnesota, United States

${ }^{5}$ Clinic of Orthopaedic and Paediatric Orthopaedics, Medical University of Lodz, Poland

Address for correspondence: Łukasz Olewnik, PhD, Department of Anatomical Dissection and Donation, Medical University of Lodz, Poland, e-mail: lukasz.olewnik@umed.lodz.pl

\begin{abstract}
Background: The biceps brachii (BB) muscle is one of the three muscles located in the anterior compartment of the of the arm. It insertion consists of two parts. The first part - main tendon — attached in the radial tuberosity and the second part — lacertus fibrosus (LF) — in the fascia of the forearm flexors. The intention of research was to reveal the morphological diversity of the insertion of this muscle. Thanks to the results of this work, have been created a classification of the distal attachment of BB. The results of that research can be used to further develop surgical procedures in the given region.
\end{abstract}

Materials and methods: Eighty (40 left, and 40 right, 42 female, 38 male) upper limbs fixed in $10 \%$ formalin solution were examined.

Results: Was observed three types of the insertion of the BB. Type I was characterized by a single tendon and occurred most frequently in $78.75 \%$ of the examined limbs. The second most common type was Type II which was characterized by a double tendon and was observed in $13.75 \%$ of all the limbs. The last and least common was Type III which was characterized by three tendons and occurred in $7.5 \%$ of the examined limbs. Additionally, the type of lacertus fibrosus (LF) was analyzed. In eight (10\%) specimens it was absent, i.e. in 
two specimens with type II insertion and six specimens with type III, p $=0.0001$. Therefore, it may be deduced that Type III BB insertion tendon predisposes to LF deficiency.

Conclusions: The biceps brachii tendon is characterized by high morphological variability. The new classification proposes three types of distal attachment: type I — one tendon; type II — two separated band-shaped tendons; type III — three separated band-shaped tendons. The presence of Type III BB tendon predisposes to a lack of LF.

\section{Key words: biceps brachii, biceps brachii tendon, lacertus fibrosus, bicipital aponeurosis, new classification}

\section{INTRODUCTION}

The anterior compartment of the arm consists of three muscles: the biceps brachii (BB), brachialis and coracobrachialis muscle. The BB usually consists of two heads: long and short [28]. The short head of the BB, together with the coracobrachialis muscle, originates from the apex of the coracoid process of the scapula, whereas the long head of the BB originates from the supra-glenoid tubercle of the scapula [28]. The proximal tendons belong to long head of biceps brachii and short head of biceps brachii transform in to muscle tissue that form two muscle bellies. In the distal part, those separated muscle bellies connect together.[3,6,7]

Insertion of biceps brachii consists of two components. One of it is a tendon attached into the radial tuberosity, and the second component being the lacertus fibrosus (LF) which fuses with the fascia of the forearm flexors.[6,7]

The primary functions of the BB are flexion of the elbow and supination of the forearm. In fact, the BB is the prime supinator of the forearm. Since it crosses the glenohumeral joint, it also assists in the shoulder flexion. Depending on the angle of the elbow, the BB performs different actions to cause movements of the upper limb. For example, if the elbow is extended, the BB is a pure elbow flexor until it reaches 90-degree flexion, while at 90 degrees flexion and with the forearm supinated, it produces elbow flexion most efficiently. Also, at 90-degree flexion and with the forearm pronated, the BB becomes the primary forearm supinator [37]. The lacertus fibrosus, on the other hand, has a more complicated function. It is believed that it increases the tension of the main tendon of the $\mathrm{BB}$; it also protects the median nerve and brachial artery running posteriorly[8, 11, 23, 39]. In addition, it plays a significant role in the reinforcement of the antebrachial fascia [23, 37]. 
The BB is characterized by morphological variability, both in the number of muscle bellies [1, 5, 11, 16, 18, 21, 22] (48), proximal attachments [3, 15, 19, 37, 43] (49), and the variability of its distal attachment, which is much less frequently described in the literature $[8,23,39](50)$.

Studies based on the variability in the types of biceps brachii bellies have a significant impact over this research. It could be said whether the number of bellies indicate amount of insertion parts. Also imaging research, e.g. in case of BB insertion rupture / tear, are essential for ongoing research. When imaging, the damaged tendon can be felt superficially (palpation). Examination of the anatomical variant in detail will allow for more accurate imaging studies. (51)

The previous available studies of the insertion of the biceps brachii assess, for example,the arrangement of the distal portion of biceps brachii and the points of reference, this serves in research of relationship between heads of biceps brachii and its insertion. It would have a potential clinical value to clarify the particular arrangement of the muscle bellies and tendon fibres. May affect the forces exerted on the distal tendon of insertion (46). Another work, tries to test the tendon footprint. Decreased radial tuberosity height effectively reduces the biceps supination of forearm, thereby limiting the peak supination torque and ability of the biceps to do work (47).

As a result of the analysis of the available studies on the distal attachment of the biceps brachii muscle, there were no measurements such as width, length, thickness according to direct type of insertion: one band, two bands, three bands. Also there was lack information about any correlation between the type of insertion and the superficial LF layer shown in results of measurement as width, length, thickness. Whether there are relationships between the type of trailer and gender or body side? Will any of the types show clearly different dimensions (width, thickness, length) from the others? This study remedies these gaps.

The biceps brachii muscle is exposed to frequent overloads. This leads to consecutive micro-injuries, which in turn trigger inflammation and subsequent biceps tendinopathy. A significant occurrence of loads on this muscle may be indicated by the fact that the rupture of the tendon of the head of a long biceps can happen at any age. Many sports aimed at using the strength of the upper limbs lead to a significant load on the work of the biceps brachii muscle. In the first place may be one-handed disciplines such as badminton, arm wrestling and twohanded such as ice hockey, tennis. In second place were sports involving throwing, e.g. 
American football, baseball. [15, 19, 37]. Distal tendon ruptures are diagnosed less frequently [25].

Injury to the distal biceps brachii tendon is very common in the fourth to sixth decade of life. It usually occurs in the dominant arm of men.[24,26] The most common cause of such damage is a sudden exertion of an eccentric force on the supinated forearm at the moment when the biceps brachii muscle is tense or partially tense [26,27]. In addition, the irregularity of the radial tuberosity can lead to damage to the attachment of the distal biceps muscle.[38]

Examination and anatomical classification of this area due to the multiplicity of damage and the subsequent necessity to perform insertion reconstruction treatments will help in better preparation for the repair plan.[27,38]

The main objective of this study is to provide the measurements that were mentioned in the previous paragraphs and answer the questions This information could potentially assist in detecting a predisposition to developing tendon injury, if such a relationship were established. Also the purpose of the present study was to characterize the possible variations in the morphology of the distal attachments of the $\mathrm{BB}$ and to draw relevant conclusions with regard to an accurate classification of the area that can be useful for improved evaluation of imaging and for planning surgical procedures in the region.

The hypothesis was that there would be variation in the distal BB morphology and that a classification system could be developed. The clinical importance of biceps brachii muscle gives us motivation to carry out this research with an aim to determine variation of biceps brachii insertion.

\section{MATERIALS AND METHODS}

An electronic digital caliper was used for all measurements (Mitutoyo Corporation, Kawasaki-shi, Kanagawa, Japan), and each measurement was performed twice with an accuracy of up to $0.1 \mathrm{~mm}$. The Bioethics Committee of the Medical University of Lodz (resolution RNN/1337/20/KE) approved the study protocol. All methods and techniques used during carrying out the research were in accordance with the protocol approved above. The cadavers belonged to the Department of Anatomical Dissection and Donation of the Medical University of Lodz, Poland.

Eighty (40 left, and 40 right; 42 female, 38 male) upper limbs fixed in $10 \%$ formalin solution were examined. The mean age of the cadavers at death was 77.9 years $(\mathrm{SD}=22.5)$ (53-95) - (Central European population). The cadavers were the property of the Department 
of Anatomical Dissection and Donation, Medical University of Lodz, Poland, having been obtained as donation to the university anatomy program. Any upper limbs with evidence of surgical intervention in the dissected area were excluded. All dissection procedures in the shoulder and arm area were performed in accordance with a pre-established protocol [29, 30, 32-35, 44, 45].

Dissection began with the removal of the skin and superficial fascia from the area of the shoulder and anterior and medial side of the arm and the anterior side of the forearm. The next stage included visualization of the lateral, medial and posterior cords of the brachial plexus, and visualization of both biceps brachii, coracobrachialis, and brachialis muscles. Then, the site of the lacerum was carefully checked. After checking and measuring the lacerum, the muscles of the anterior forearm group were delaminated to locate and check as well as to measure the tendons and examine their insertion. Next, all the structures were thoroughly cleaned [31, 37, 40].

Upon dissection, the following morphological features of the BB were assessed:

- the morphology of the BB lacerum:

- (proximal)width and thickness at the beginning at the point of detachment from the terminal tendon line

- (distal) width and thickness at the end of lacertum fibrosum,the type of BB insertion (indicated by number of tendons)

- morphometric measurements of the BB.:

- (distal) width and thickness at the point of attachment to radial tuberosity

- Length from attachment radial tuberosity till start of muscle belly

The procedure of BB dissection was performed in accordance with the following principles:

- When clearing the BB, attention should be paid to the presence of its accessory heads.

- When checking the BB, the distal part should be carefully studied for the presence of coracobrachialis longus muscle and for the relationships between the median nerve and musculocutaneous nerve.

\section{Statistical analysis}

A Chi ${ }^{2}$ test were used to compare differences in insertion types between genders, sides of the body. The Shapiro-Wilk test was used to check the normality of the data. The MannyWhitney test and the Wilcoxon test were used to compare data on gender and sides of the 
body. In order to compare data on measurements of the indicated types of insertion, we used The Manny-Whitney test and the Kruskal-Wallis test with the appropriate post hoc test.

For analysis, Statistica 13.1 was employed. We considered that P-value lower than 0.05 was statistically significant. In addition, Bonferroni correction was used for multiple comparisons.

\section{RESULTS}

\section{Anatomic study}

In all 80 limbs, the BB insertion was present and suitable for morphological analysis. Based on a morphological analysis, the following types of BB insertion were differentiated:

1. Type I - was characterized by a single tendon and insertion into the radial tuberosity of the radius. This type was found in 63 upper limbs (78.75 \%) - (34 females and 29 males; 32 right and 31 left) - Fig. 1a, Fig. 1b.

2. Type II -was characterized by a double tendon and insertion into the radial tuberosity of the radius. This type was observed in 11 limbs (13.75 \%) - (2 females and 9 males; 5 right and 6 left) - Fig. 2a, Fig. 2b.

3. Type III - was characterized by a triple tendon and insertion into the radial tuberosity. This type was recognised in 6 upper limbs (7.5 \%) - (6 females and 0 males; 3 right and 3 left) - Fig.3a, Fig. 3b.

Type II was significantly more common in males, whereas type III in females $(p=0.0013)$. There was no significant difference in the frequency of type occurrence between side of the body $(\mathrm{p}=09479)$.

Additionally, the type of LF was analysed - Fig, 4. In eight specimens it was absent (10\% -8 females and 0 males, $\mathrm{p}=0.2686 ; 4$ right and 4 left; in two specimens with type II insertion and six specimens with type III, $\mathrm{p}=0.0001$ ).

Comparison of morphological data between genders and side of the body is presented in Table 1. Table 2 demonstrates data on insertion types.

According to a post-hoc analysis, the length of tendon I in type I and III is almost equal and its higher than in type II, while tendon I width was greater in type I than in types II and III.

Table 1. Morphometric parameters according to gender and side of the body 


\begin{tabular}{|c|c|c|c|c|c|c|}
\hline \multirow{2}{*}{ Parameter } & \multicolumn{2}{|l|}{ Sex } & \multirow{2}{*}{$\begin{array}{l}\text { value } \\
\text { val }\end{array}$} & \multicolumn{2}{|c|}{ Side of the body } & \multirow{2}{*}{$\begin{array}{l}P \\
\text { value }\end{array}$} \\
\hline & Females & Males & & Right & Left & \\
\hline Tendon I length & $\begin{array}{l}66.08 \\
(12.08)\end{array}$ & $\begin{array}{l}65.92 \\
(12.30)\end{array}$ & 0.7396 & $\begin{array}{l}66.08 \\
(12.09)\end{array}$ & $\begin{array}{l}65.93 \\
(12.28)\end{array}$ & 0.9037 \\
\hline Tendon I width & $\begin{array}{l}7.83 \\
(3.94)\end{array}$ & $\begin{array}{l}6.04 \\
(225)\end{array}$ & 0.0313 & $\begin{array}{l}7.01 \\
(3,38)\end{array}$ & $\begin{array}{l}6.94 \\
(3.36)\end{array}$ & 0.2736 \\
\hline Tendon I thickness & $\begin{array}{l}2.52 \\
(0.65)\end{array}$ & $\begin{array}{l}2.54 \\
(0.67)\end{array}$ & 0.9539 & $\begin{array}{l}2.54 \\
(0.67)\end{array}$ & $\begin{array}{l}2.52 \\
(0.65)\end{array}$ & 0.8945 \\
\hline Tendon II length & $\begin{array}{l}59.92 \\
(9.74)\end{array}$ & $\begin{array}{l}55.78 \\
(2.76)\end{array}$ & 0.0922 & $\begin{array}{l}58.22 \\
(7.26)\end{array}$ & $\begin{array}{l}57.29 \\
(7.29)\end{array}$ & 0.4008 \\
\hline Tendon II width & $\begin{array}{l}2.53 \\
(0.55)\end{array}$ & $\begin{array}{l}3.98 \\
(0.58)\end{array}$ & 0.0012 & $\begin{array}{l}3.32 \\
(1.09)\end{array}$ & $\begin{array}{l}3.27 \\
(0.83)\end{array}$ & 0.7353 \\
\hline Tendon II thickness & $\begin{array}{l}1.78 \\
(0.20)\end{array}$ & $\begin{array}{l}2.33 \\
(0.38)\end{array}$ & 0.0006 & $\begin{array}{l}2.06 \\
(0.45)\end{array}$ & $\begin{array}{l}2.09 \\
(0.40)\end{array}$ & 0.8886 \\
\hline Tendon III length & $\begin{array}{l}66.46 \\
(3.21)\end{array}$ & & & $\begin{array}{l}66.37 \\
(3.59) \\
\end{array}$ & $\begin{array}{l}66.55 \\
(3.58) \\
\end{array}$ & 1.0000 \\
\hline Tendon III width & $\begin{array}{l}1.91 \\
(0.30)\end{array}$ & & & $\begin{array}{l}1.76 \\
(0.22)\end{array}$ & $\begin{array}{l}2.06 \\
(0.33)\end{array}$ & 0.1088 \\
\hline Tendon III thickness & $\begin{array}{l}1.39 \\
(0.12)\end{array}$ & & & $\begin{array}{l}1.35 \\
(0.12)\end{array}$ & $\begin{array}{l}1.43 \\
(0.11)\end{array}$ & 0.1088 \\
\hline Lacertus fibrosus Length & $\begin{array}{l}38.58 \\
(8.76)\end{array}$ & $\begin{array}{l}36.83 \\
(10.19)\end{array}$ & 0.4272 & $\begin{array}{l}37.49 \\
(9.63) \\
\end{array}$ & $\begin{array}{l}37.91 \\
(9.45) \\
\end{array}$ & 0.0218 \\
\hline $\begin{array}{l}\text { Lacertus fibrosus width } \\
\text { proximal }\end{array}$ & $\begin{array}{l}7.62 \\
(3.98)\end{array}$ & $\begin{array}{l}6.41 \\
(3.27)\end{array}$ & 0.2281 & $\begin{array}{l}6.93 \\
(3.64)\end{array}$ & $\begin{array}{l}7.10 \\
(3.74)\end{array}$ & 0.3419 \\
\hline $\begin{array}{l}\text { Lacertus fibrosus } \\
\text { thickness proximal }\end{array}$ & $\begin{array}{l}1.15 \\
(0.63)\end{array}$ & $\begin{array}{l}1.11 \\
(0.41)\end{array}$ & 0.9551 & $\begin{array}{l}1.13 \\
(0.53)\end{array}$ & $\begin{array}{l}1.12 \\
(0.54)\end{array}$ & 0.5043 \\
\hline $\begin{array}{l}\text { Lacertus fibrosus width } \\
\text { distal }\end{array}$ & $\begin{array}{l}12.39 \\
(6.80)\end{array}$ & $\begin{array}{l}12.26 \\
(10.05)\end{array}$ & 0.3054 & $\begin{array}{l}12.59 \\
(8.83)\end{array}$ & $\begin{array}{l}12.07 \\
(8.32)\end{array}$ & 0.9249 \\
\hline $\begin{array}{l}\text { Lacertus fibrosus } \\
\text { thickness distal }\end{array}$ & $\begin{array}{l}1.67 \\
(0.70)\end{array}$ & $\begin{array}{l}1 ., 58 \\
(0.40) \\
\end{array}$ & 0.7269 & $\begin{array}{l}1.60 \\
(0.55)\end{array}$ & $\begin{array}{l}1.64 \\
(0.60) \\
\end{array}$ & 0.3339 \\
\hline
\end{tabular}

Table 2. Morphometric parameters according to insertion types

\begin{tabular}{|l|l|l|l|l|}
\hline \multirow{2}{*}{ Parameter } & \multicolumn{2}{l}{ Insertion types } & \multirow{2}{*}{ P value } \\
\cline { 2 - 5 } & I & II & III & \\
\hline Tendon I length & $68.76(11.72)$ & $51.83(5.30)$ & $63.09(3.27)$ & 0.0001 \\
\hline Tendon I width & $7.93(3.10)$ & $3.91(1.24)$ & $2.60(0.10)$ & 0.0001 \\
\hline Tendon I thickness & $2.62(0.65)$ & $2.23(0.72)$ & $2.09(0.12)$ & 0.001 \\
\hline Tendon II length & & $53.77(5.12)$ & $65.00(3.04)$ & 0.0011 \\
\hline Tendon II width & & $3.87(0.58)$ & $2.24(0.19)$ & 0.0011 \\
\hline Tendon II thickness & & $2.18(0.48)$ & $1.87(0.10)$ & 0.0392 \\
\hline Tendon III length & & & $66.46(3.21)$ & \\
\hline Tendon III width & & & $1.91(0.30)$ & \\
\hline Tendon III thickness & & & $1.39(0.12)$ & \\
\hline Lacertus fibrosus Length & $39.07(9.05)$ & $28.09(6.61)$ & & 0.0003 \\
\hline
\end{tabular}




\begin{tabular}{|l|l|l|l|l|}
\hline Lacertus fibrosus width proximal & $7.17(3.88)$ & $5.96(1.16)$ & & 0.8782 \\
\hline $\begin{array}{l}\text { Lacertus fibrosus thickness } \\
\text { proximal }\end{array}$ & $1.13(0.56)$ & $1.13(0.15)$ & 0.7143 \\
\hline Lacertus fibrosus width distal & $12.90(8.91)$ & $8.33(2.97)$ & & 0.3852 \\
\hline Lacertus fibrosus thickness distal & $1.60(0.57)$ & $1.79(0.55)$ & & 0.4641 \\
\hline
\end{tabular}

\section{DISCUSSION}

The BB muscle, probably arise from a common premuscle mass with coraccbrachialis, and brachialis. All three muscles in very early stages are intimately fused together. The origin of the long and short head of the BB at this early prenatal life are close together, and later growth of the scapula will separate them. The distal insertion of the common muscle mass varies at the later time than the proximal. (53)

In most cases the distal BB tendon is described as easily divided into two components; an anterior layer linked to the short head, and a posterior layer linked to the long head (54)

The key value of the work is presentation of a new systematic classification of the distal biceps brachii insertion based on anatomical dissection. It should be emphasized that this is the first classification of this type that is necessary for orthopedists and surgeons operating in this area. It can also be useful for physiotherapists when planning rehabilitation procedures and radiologist for imaging analysis.[6, 7]

Many studies are focused on the measurement of the tendon and lacertus fibrosus [11, 39]. Eames et al. [13] and also Snoeck et al. observed that LF superficial layer was present in all tested limbs. In the present study, the absence of LF superficial layer was observed in 10\%. [39]

In the present study, we have noticed that LF originates both from the long and short head of $\mathrm{BB}$, extends over the pronator teres and connects to the fascia of the forearm, as described earlier by other researchers. [3,6,7] (39). The finding that the short and long head in the myotendinous junction was the origin of the LFs was crucial as it identified LF as an important landmark that allows identification of the short head of the tendon and, therefore, correct orientation of the entire distal biceps tendon during surgical repair.(39, 46,51) Athwal et al. in their research describes that the short head of biceps brachii is the starting point of LF. On the other hand, Dirim et al. [12] describe formation of the LF by combining superficial tendon-type fibers arising from both heads of the biceps muscle of the arm. In presented research LF was described same as Dirim did. 
The most thorough examination was carried out by Eames et al. [13] he pointed out that LF is formed from the combination of three layers. On the long head from its radial side forms the first and thickest layer. The second layer is the middle layer. It is formed from the combination of aponeurosis and a short head. It has the form of loose tissue [13]. The third layer starts as in the case of the first layer only deeper. In addition, it is strengthened by a superficial layer of aponeurosis.[13].

Compare presented research to the work of Snoeck et al, the measurement of the LF length was made as a central dimension (according to the manuscript of Snoeck et al) and it appear no significant statistical differences. Lacertus fibrosus did not show significant variations related to gender, Same result ocurred in research of Forthman et al. (47)

Unfortunately width and thickness are unable to be compared. Measuring equipment and measurement procedures may have differed betwen studies.Most research on the distal part of the BB is limited to performing narrowed morphometric measurements of the tendon as well as describing the LF and the relationship between the BB and LF tendons $[8,11,13$, $20,25]$.

Athwal et al. [2] described that it is possible to "separate" the tendon fibers belonging to the short or long head of BB. They specified two attachment sites on the radial tuberosity of the radius. The superior aspect is occupied by the long head of BB and the inferior aspect is occupied by the short head of BB [2]. Also Forthman et al. (47) examined radial tuberosity for the extent of insertion of biceps brachii. The biceps tendon footprint lies over the apex of the tuberosity, with the geometric center of the tendon inserting in less pronation. (47)

Unlike Athwal et al., we did not observe the possibility of "separating" tendons from each other. We strongly believe that the division into the superior and inferior aspect of insertion of the short and long head of BB is not exceptionally reliable, due to the fact that subsequent tests should be based on the possibility of checking the distal attachment, e.g. for $\mathrm{BB}$ with three, four and e.g. five heads.

In the present study we observed three types of BB tendon insertions. Therefore we proposed a three-folded classification. Type I is characterized by a single tendon and occurred most frequently (in 78.75\%) in the examined limbs. This type was commonly described by vast amount of other researchers $(2,5,6,12,47)$ The second most common type is Type II which was characterized by a double tendon and was observed in $13.75 \%$ of all the limbs. Also this type was already mentioned in other researches $(50,51)$. The last and rarest one was Type III which was characterized by three tendons and occurred in $7.5 \%$ of the examined limbs. Beside its rarity none ever before described that type. 
Additionally, the type of LF was analyzed. Therefore, it may be deduced that Type III BB insertion tendon predisposes to LF deficiency. No one ever before described such comparison. Statistical differences were also observed in the study, e.g., , the length of tendon I in type I and III is almost equal and its higher than in type II , while tendon I width was greater in type I than in types II and III. Thus, it can be speculated that Type I BB tendon insertions are least likely to be affected by rupture or fiberization as compared to types II and III.

Knowledge of the anatomical variant of BB insertion will allow for a more accurate diagnostic examination of the case.(51,52). Such as:

- Tendon rapture(can be complete or partial)

- Disinsertion of the tendon( tendon detachment from its insertion may be partial or complete)

- Tendinopathy (It causes loss of the fibrillar aspect of the tendon, the structure of which appears disorganized and accompanied by diffuse, heterogeneous thickening.)

- Enthesopathy (associated with hypoechoic swelling that involves one or all of the tendons that) insert on the radial tuberosity.

- Bursitis ( Distention and inflammation of the tendon bursa, which allows the tendon to roll around radial tuberosity)

- Peritendinopathy (chronic pain have tendon sheath effusions that are not associated with tendon anomalies)

Unfortunately, we do not have information about side of limb domination, it would be interesting comparison. However, an anatomical comparison of left to right also seems valid. We assume in advance that men exhibit a greater muscle mass of the biceps brachii muscle, so it is interesting which type will be dominant depending on gender, It could be assumed that it will be the most durable type.

Women have naturally smaller muscle tissue, so it can be assumed that the muscle naturally causes less stress on the insertion, so a softer (weaker) attachment is enough for effective work. So it appears that type III is the weakest among those three.

An important piece of information for better planning of surgical procedures for repairing the raptures of the distal attachment of the biceps brachii tendon is knowledge of its size and location. Skillfully idling the course and orientation of this attachment will support surgeons in determining the size of the partial tear in the thickness of this tendon and indicating the associated muscles. Nowadays, surgical procedures to repair the detachment of the biceps tendon are performed on a daily basis. Tendon fracture repair procedures are 
performed using the technique of one incision (usually suture anchors are used here) or the technique of two cuts. (47)

Broken tendons are subject to several treatment techniques: one cut technique (use of seam anchors), two-cut technique (using bone tunnels), biotendinosis screw for fixation and endobuttons. [4, 9, 10, 17, 27, 41, 42]. Different methods of double incision (standard and modified) are characterized by a different dimension of showing the ulnar periosteum. The Morrey technique (muscle splitting technique) reduces the possibility of synostosis. [14, 36]. It turned out that against the induction of nerve palsy (radial or lateral antebrachial cutaneous nerve) nor the heterotopic ossification does not protect the anterior small incision of the cubital fossa with the execution of muscle splitting technique. [42].

Our research is not without its limitations. In the first place, it would be necessary to indicate the non-uniform nature of the classification, which is influenced by morphological details, such as shape or surface of the insertion. In the second place, we should mention that as the results of anatomical research we are able to present a jumble of inconsistencies and the continuation of this work should be studies checking the probable value of using ultrasound and MRI to image and map the area that has been studied in our work. Performing a biomechanical test of each type of tendon would allow to confirm the indication of which of the types is stronger and whether the differences in the range of morphometric measurements are significant. The study also lacked indications of tendon belonging to muscle heads in type 2 and type 3 . Another weakness of these studies is the failure to assess the deep LF layers. Despite the indicated limitations, this work brings with it knowledge that allows for a more accurate definition of search in this area of research / treatment. It also indicates a uniform classification and nomenclature, helping in the work of future researchers or surgeons moving in this region.

\section{CONCLUSIONS}

The biceps brachii tendon is characterized by high morphological and topographical variability. Its insertion can be affected by different types of lesions, some of which are frequently misdiagnosed on the basis of the clinical examination. Therefore it seems very important to develop the new BB insertion classification. It proposes three types of distal attachment (I-III). Additionally, an equally important piece of information is lack of lacertus fibrosus in presence of Type III BB tendon..

\section{Ethical approval and consent to participate}


The Bioethics Committee of the Medical University of Lodz (resolution RNN/1337/20/KE) approved the study protocol. The cadavers belonged to the Department of Anatomical Dissection and Donation of the Medical University of Lodz, Poland. Informed Consents were obtained from all participants before they died.

\section{Acknowledgements}

The authors sincerely thank those who donated their bodies to science so that anatomical research could be performed. Results from such research can potentially increase mankind's overall knowledge that can then improve patient care. Therefore, these donors and their families deserve our highest gratitude.

\section{Funding}

The authors have no financial or personal relationship with any third party whose interests could be positively or negatively influenced by the article's content. This research did not receive any specific grant from funding agencies in the public, commercial, or notfor-profit sectors.

Conflict of interest: Friedrich Paulsen receives royalties from Elsevier for the $24^{\text {th }} \mathrm{Ed}$. of the anatomy atlas "Sobotta” and the 'Sobotta Textbook of Anatomy' $2^{\text {nd }}$ Ed. The authors declare that they have no competing interests.

\section{REFERENCES}

1. Al-Kushi G (2013) Anatomical study of the third head of biceps brachii muscle and its innervation by median nerve in human dissection. J Clin Med Res 5:47-52. doi: 10.5897/jcmr12.017

2. Athwal GS, Steinmann SP, Rispoli DM (2007) The Distal Biceps Tendon: Footprint and Relevant Clinical Anatomy. J Hand Surg Am 32:1225-1229. doi: 10.1016/j.jhsa.2007.05.027

3. Audenaert EA, Barbaix EJ, Van Hoonacker P, Berghs BM (2008) Extraarticular variants of the long head of the biceps brachii: A reminder of embryology. J Shoulder Elb Surg 17:114-117. doi: 10.1016/j.jse.2007.06.014

4. Balabaud L, Ruiz C, Nonnemacher J, Seynaeve P, Kehr P, Rapp E (2004) Repair of distal biceps tendon ruptures using a suture anchor and an anterior approach. J Hand Surg Am 29 B:178-182. doi: 10.1016/j.jhsb.2003.07.002

5. Ballesteros LE, Forero PL, Buitrago ER (2014) Evaluation of Additional head of biceps brachii: A study with autopsy material. Folia Morphol 73:193-198. doi: 
10.5603/FM.2014.0028

6. Bardeen C (1905) Studies of the development of the human skeleton. AmerJ Anat 265302

7. Bardeen C (1906) Development and variation of the musculature of the inferior extremity and the neighboring regions of the trunk in man. Am J Anat 6:259-390. doi: 10.1002/aja.1000060108

8. Blasi M, De La Fuente J, Martinoli C, Blasi J, Pérez-Bellmunt A, Domingo T, MiguelPérez M (2014) Multidisciplinary approach to the persistent double distal tendon of the biceps brachii. Surg Radiol Anat 36:17-24. doi: 10.1007/s00276-013-1136-y

9. Camp CL, Voleti PB, Corpus KT, Dines JS (2016) Single-Incision Technique for Repair of Distal Biceps Tendon Avulsions With Intramedullary Cortical Button. Arthrosc Tech 5:e303-e307. doi: 10.1016/j.eats.2016.01.002

10. Citak M, Backhaus M, Seybold D, Suero EM, Schildhauer TA, Roetman B (2011) Surgical repair of the distal biceps brachii tendon: A comparative study of three surgical fixation techniques. Knee Surgery, Sport Traumatol Arthrosc 19:1936-1941. doi: 10.1007/s00167-011-1591-0

11. Cucca YY, McLay SVB, Okamoto T, Ecker J, McMenamin PG (2010) The biceps brachii muscle and its distal insertion: Observations of surgical and evolutionary relevance. Surg Radiol Anat 32:371-375. doi: 10.1007/s00276-009-0575-y

12. Dirim B, Brouha SS, Pretterklieber ML, Wolff KS, Frank A, Pathria MN, Chung CB (2008) Terminal bifurcation of the biceps brachii muscle and tendon: Anatomic considerations and clinical implications. Am J Roentgenol 191:1-22. doi: 10.2214/AJR.08.1048

13. Eames MHA, Bain GI, Fogg QA, Van Riet RP (2007) Distal biceps tendon anatomy: A cadaveric study. J Bone Jt Surg - Ser A 89:1044-1049. doi: 10.2106/JBJS.D.02992

14. Eardley WGP, Odak S, Adesina TS, Jeavons RP, McVie JL (2010) Bioabsorbable interference screw fixation of distal biceps ruptures through a single anterior incision: A single-surgeon case series and review of the literature. Arch Orthop Trauma Surg 130:875-881. doi: 10.1007/s00402-009-0974-X

15. Enad JG (2004) Bifurcate origin of the long head of the biceps tendon. Arthrosc - J Arthrosc Relat Surg 20:1081-1083. doi: 10.1016/j.arthro.2004.09.003

16. GREIG HW, ANSON BJ, BUDINGER JM (1952) Variations in the form and attachments of the biceps brachii muscle. Q Bull Northwest Univ Med Sch 26:241244

17. Gupta RK, Bither N, Singh H, Kapoor S, Chhabra A, Garg S (2012) Repair of the torn distal biceps tendon by endobutton fixation. Indian J Orthop 46:71-76. doi: 10.4103/0019-5413.91638

18. Ilayperuma I, Nanayakkara G, Palahepitiya N (2011) Incidence of Humeral Head of Biceps Brachii Muscle: Anatomical Insight. Int J Morphol 29:221-225. doi: 10.4067/s0717-95022011000100037

19. Jeong JY, Park SM, Park YE, Yoo JC (2017) Morphological classification of anatomical variants of the intra-articular portion of the long head of the biceps brachii tendon and analysis of the incidence and the relationship with shoulder disease for each subtype. J Orthop Surg 25:1-6. doi: 10.1177/2309499017742207 
20. Joshi SD, Yogesh AS, Mittal PS, Joshi SS (2014) Morphology of the bicipital aponeurosis: A cadaveric study. Folia Morphol 73:79-83. doi: 10.5603/FM.2014.0011

21. Kopuz C, Sancak B, Özbenli E (1999) On the incidence of third head of biceps brachii in turkish neonates and adults. Acta Anat Nippon 74:301-305

22. Kosugi K, Shibata S, Yamashita H (1992) Supernumerary head of biceps brachii and branching pattern of the musculocutaneus nerve in Japanese. Surg Radiol Anat 14:175-185. doi: 10.1007/BF01794898

23. Landa J, Bhandari S, Strauss EJ, Walker PS, Meislin RJ (2009) The effect of repair of the lacertus fibrosus on distal biceps tendon repairs: A biomechanical, functional, and anatomic study. Am J Sports Med 37:120-123. doi: 10.1177/0363546508324694

24. Lee SE, Jung C, Ahn KY, Nam K Il (2011) Bilateral asymmetric supernumerary heads of biceps brachii. Anat Cell Biol 44:238. doi: 10.5115/acb.2011.44.3.238

25. Mazzocca AD, Cohen M, Berkson E, Nicholson G, Carofino BC, Arciero R, Romeo AA (2007) The anatomy of the bicipital tuberosity and distal biceps tendon. J Shoulder Elb Surg 16:122-127. doi: 10.1016/j.jse.2006.04.012

26. McDonald LS, Dewing CB, Shupe PG, Provencher MT (2013) Disorders of the proximal and distal aspects of the biceps muscle. J Bone Jt Surg - Ser A 95:1235-1245. doi: 10.2106/JBJS.L.00221

27. Miyazaki AN, Fregoneze M, Santos PD, da Silva LA, do Val Sella G, Duarte DC, Checchia SL (2014) Functional evaluation of patients with injury of the distal insertion of the biceps brachii muscle treated surgically. Rev Bras Ortop (English Ed 49:129133. doi: 10.1016/j.rboe.2014.03.015

28. Moore K, Arthur F, Dalley I, Anne M, Agur (2013) Clinically Oriented Anatomy, 7th ed. Lippincott Williams\&Wilkins

29. Olewnik $€$ (2019) Is there a relationship between the occurrence of frenular ligaments and the type of fibularis longus tendon insertion? Ann Anat 224:47-53. doi: 10.1016/j.aanat.2019.03.002

30. Olewnik Ł, Gonera B, Kurtys K, Podgórski M, Polguj M, Topol M (2019) A proposal for a new classification of the fibular (lateral) collateral ligament based on morphological variations. Ann Anat 222:1-11. doi: 10.1016/j.aanat.2018.10.009

31. Olewnik Ł, Karauda P, Gonera B, Kurtys K, Tubbs RS, Paulsen F, Szymański R, Polguj M (2021) Impact of plantaris ligamentous tendon. Sci Rep in press:1-8

32. Olewnik Ł, Kurtys K, Gonera B, Podgórski M, Sibiński M, Polguj M (2020) Proposal for a new classification of plantaris muscle origin and its potential effect on the knee joint. Ann Anat - Anat Anzeiger 151506. doi: 10.1016/j.aanat.2020.151506

33. Olewnik Ł, Paulsen F, Tubbs RS, Zielinska N, Szewczyk B, Karauda P, Polguj M (2020) Potential compression of the musculocutaneous, median and ulnar nerves by a very rare variant of the coracobrachialis longus muscle. Folia Morphol (Warsz). doi: 10.5603/fm.a2020.0085

34. Olewnik Ł, Zielinska N, Karauda P, Duparc F, Georgiev G, Polguj M The cooccurrence of a four headed coracobrachialis muscke, split coracoid process and tunnel for the median and musculocutaneous nerve: the potential clinical relevance of a very rare variation

35. Olewnik Ł, Zielinska N, Paulsen F (2020) A proposal for a new classification of soleus 
muscle morphology. Ann Anat - Anat Anzeiger 32810614. doi:

10.1016/j.aanat.2020.151584

36. Olsen JR, Shields E, Williams RB, Miller R, Maloney M, Voloshin I (2014) A comparison of cortical button with interference screw versus suture anchor techniques for distal biceps brachii tendon repairs. J Shoulder Elb Surg 23:1607-1611. doi: 10.1016/j.jse.2014.06.049

37. Podgórski M, Olewnik Ł, Rusinek M, Cichosz M, Polguj M, Topol M (2019) 'superior biceps aponeurosis'-Morphological characteristics of the origin of the short head of the biceps brachii muscle. Ann Anat 223:85-89. doi: 10.1016/j.aanat.2019.01.014

38. Seiler JG, Parker LM, Chamberland PDC, Sherbourne GM, Carpenter WA (1995) The distal biceps tendon. Two potential mechanisms involved in its rupture: Arterial supply and mechanical impingement. J Shoulder Elb Surg 4:149-156. doi: 10.1016/S10582746(05)80044-8

39. Snoeck O, Lefèvre P, Sprio E, Beslay R, Feipel V, Rooze M, Van Sint Jan S (2014) The lacertus fibrosus of the biceps brachii muscle: An anatomical study. Surg Radiol Anat 36:713-719. doi: 10.1007/s00276-013-1254-6

40. Szewczyk B, Paulsen F, Duparc F, Karauda P, Polguj M, Olewnik Ł A proposal for a new classification of coracobrachialis muscle morphology

41. Tarallo L (2014) Distal biceps tendon rupture reconstruction using muscle-splitting double-incision approach. World J Clin Cases 2:357. doi: 10.12998/wjcc.v2.i8.357

42. Tarallo L, Lombardi M, Zambianchi F, Giorgini A, Catani F (2018) Distal biceps tendon rupture: Advantages and drawbacks of the anatomical reinsertion with a modified double incision approach 11 Medical and Health Sciences 1103 Clinical Sciences. BMC Musculoskelet Disord 19:1-14. doi: 10.1186/s12891-018-2278-1

43. Vangsness CT, Jorgenson SS, Watson T, Johnson DL (1994) The origin of the long head of the biceps from the scapula and glenoid labrum. An anatomical study of 100 shoulders. J Bone Jt Surg - Ser B 76:951-954. doi: 10.1302/0301-620x.76b6.7983126

44. Zielinska N, Olewnik $€$, Tubbs RS (2020) A very rare case of an accessory subscapularis muscle and its potential clinical significance. Surg Radiol Anat. doi: 10.1007/s00276-020-02531-6

45. Zielinska N, Tubbs RS, Podgórski M, Karauda P, Polguj M, Olewnik L (2020) The subscapularis tendon: A proposed classification system. Ann Anat - Anat Anzeiger 151615. doi: 10.1016/j.aanat.2020.151615.

Figure 1. Type I of biceps brachii insertion; shBB — short head of the biceps brachii; lhBB — long head of the biceps brachii; $\mathrm{R}$ — radius bone.

Figure 2. Type II of the biceps brachii insertion; shBB — short head of the biceps brachii; lhBB — long head of the biceps brachii; $\mathrm{R}$ — radius bone. 
Figure 3. Type III of biceps brachii insertion; shBB — short head of the biceps brachii; lhBB — long head of the biceps brachii; $\mathrm{R}$ — radius bone.

Figure 4. Lacertus fibrosus; lhbb — long head of the biceps brachii; shBB — short head of the biceps brachii; MN — median nerve; BA — brachial artery; BRM — brachioradialis muscle LF — lacertus fibrosus. 


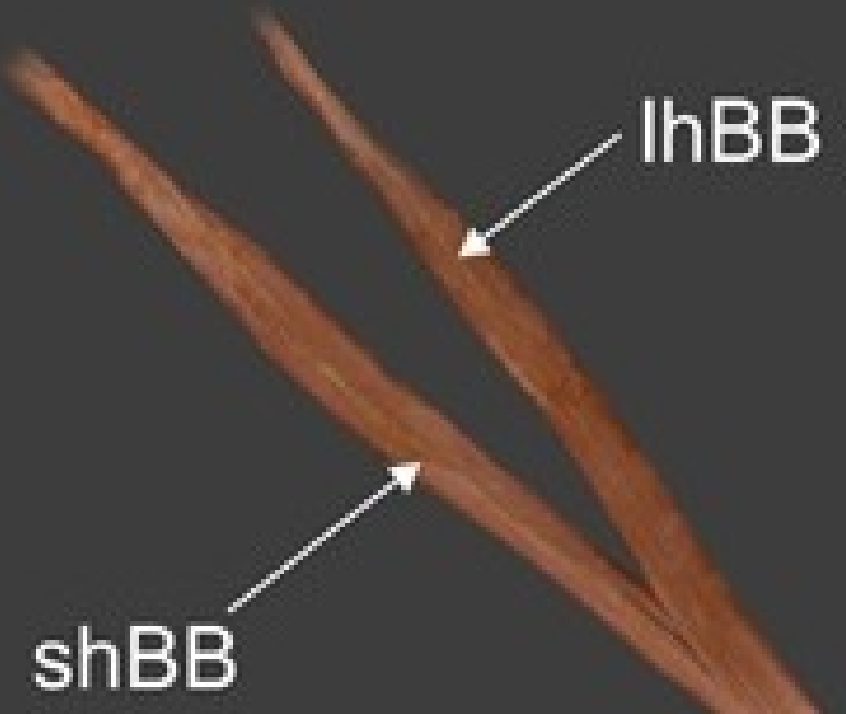

$\mathrm{R}$

풀 


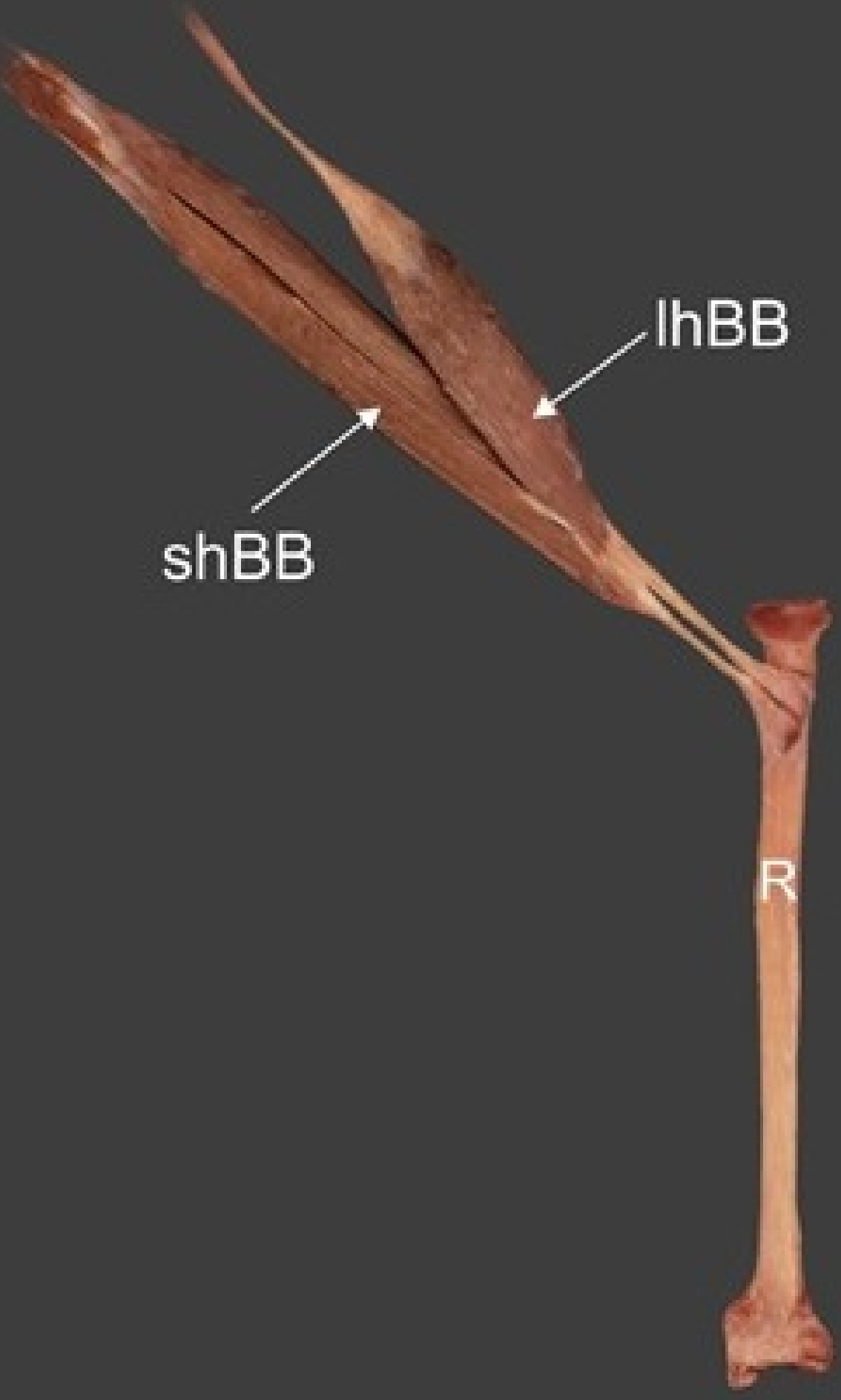


IhBB

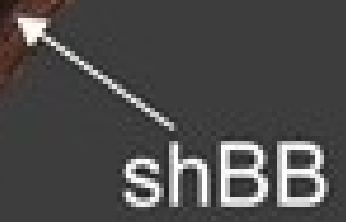

R 


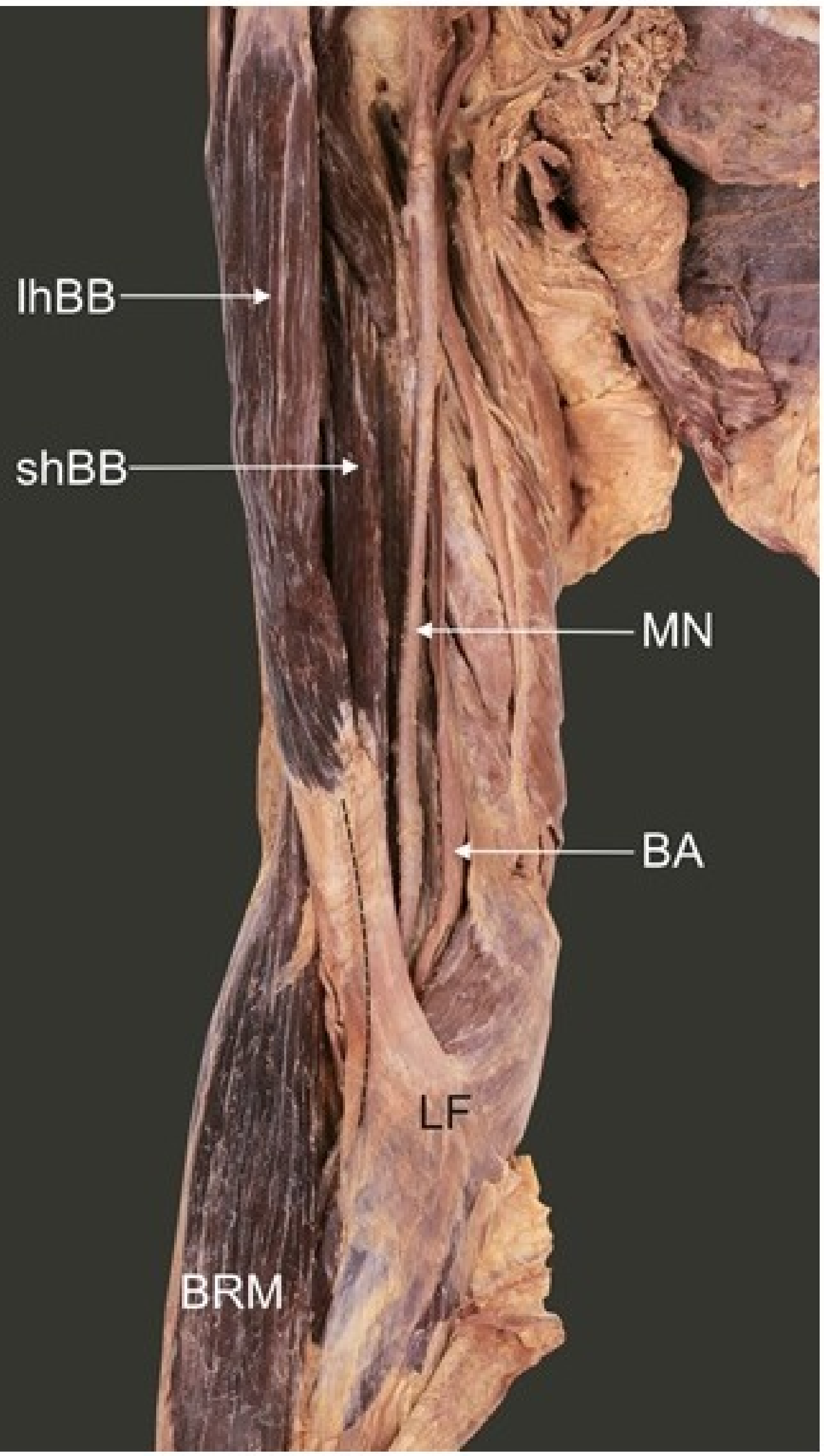

